\title{
Thormation
}

Nordic Journal of Art and Research

ISSN: 1893-2479

www.artandresearch.info

\section{The Series - Serial work in artistic research and in the didactics of the arts}

\author{
Aslaug Nyrnes $^{1}$ \\ Centre of arts, culture and communication, Bergen University College
}

\begin{abstract}
The series is a paradoxical phenomenon in artistic work. The term "series" signifies copying, repetition, reproduction and frequently even trivialization - to break with the idea of the original. However, serial work is simultaneously central both in the work of art and in the didactics of arts and crafts. Using examples in painting and ceramics, this article discusses the series as an epistemological figure and relates the reflection to questions of quality assessment and the building of theory both in the didactics of the arts and in artistic research.
\end{abstract}

Keywords: Serial work, cópia, resemblance, uniform, repetition, comparison, artistic research, artistic theory, didactics of the arts

In 2008, there was an exhibition of works by the painter Pinturicchio, or Bernardino di Betto (1454-1513), in the Galleria Nazionale dell'Umbria in Perugia. Pinturicchio is the least known of the three canonized painters from the Italian Renaissance: Raphael, Perugino and Pinturicchio. The exhibition focused on the Virgin and Child motif, or the Madonna with Child. There were approximately 30 pieces with this same motif, all by Pinturicchio. Nevertheless, in the DVD that followed the exhibition, and in the gallery bookshop, one could acquire a copy of only one of these paintings. This one painting was assumed the most interesting, the most outstanding in the collection on display.

Pinturicchio painted the same motif in approximately 30 slightly different ways. It is said that he paid particular attention to the details. One might ask what happens when one experiments with details: What differences are evident in the background of the

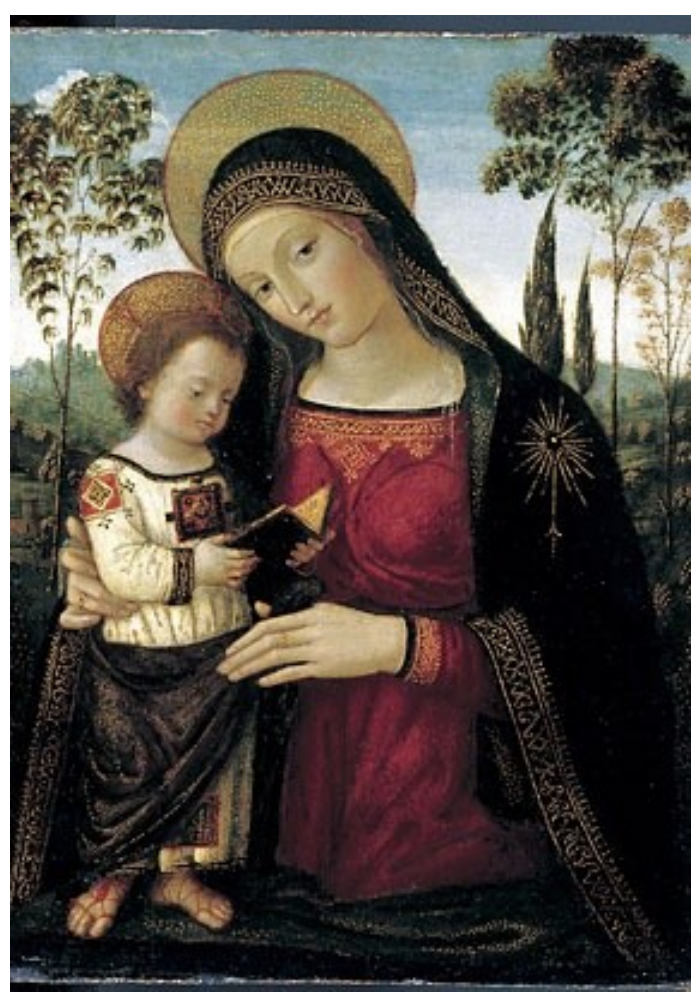

Figure 1: Pinturicchio: Madonna and the Child

\footnotetext{
${ }^{1}$ Senter for kunstfag, kultur og kommunikasjon, Høgskolen i Bergen, Landåssvingen 15, 5096 Bergen, Norway. E-mail: Aslaug.Nyrnes@hib.no
} 
painting in question? What were the limits of the experiment? How are the differences valued - by the artist, by his contemporaries and by viewers today? To gain an understanding of Pinturicchio, one needs to view the paintings in their historical and cultural context, which means focusing on the function of the motif in its religious context, a function based on ritual, or what Walter Benjamin would call the "cult value" (Benjamin, 2007, p. 33). One cannot simply talk about a free artist choosing to paint what he or she wants. In art history, we speak of conventions - religious conventions, cultural conventions and painting conventions. However, we do not know what Pinturicchio himself had to say about his work. Therefore, our reflections will be analytical and thus located outside the painting process and the work of art itself.

Pinturicchio's paintings have a serial character to them. Indeed, the series is a basic epistemological figure. We might also say that the concept of the series shapes our thinking. In this article, I explore aspects of serial work in the art field from both the production and reception perspectives. Such aspects are of tremendous interest in the didactics of the arts. Consequently, the goals of this paper are three-fold.

First, the phenomenon of series is examined and examples are provided for clarity. To operate in a series seems to be a paradoxical phenomenon in artistic work. We typically think of art as being a unique expression, one of a kind. However, the series may be understood as situated somewhere between the universal and the particular. On the one hand, it can be recognized as part of well-known processes in popular culture - samples of similar objects. It signifies and implies copying, something secondary and trivial, that has to do with an assembly line way of working or mass production, and in this respect - linked to commercialisation. On the other hand, many artists - famous artists, not merely in popular culture - have produced works in a series. Why is that true? Is it a lack of imagination? Is it laziness? Or is it a way of controlling an artistic research process? Drawing upon selected examples, I identify different types of series. I also provide a brief overview of how artistic series have been valuated differently in different historical periods and theoretical domains. At the end of the first section, I present two main theoretical perspectives on the series.

My second goal is to explore how the series, as a phenomenon, could contribute to the discussion of quality promotion in arts education. As indicated in the "wow-factor" argument, education research has revealed that art may indeed promote progress and learning in teaching other subjects as well (Bamford, 2006). Certainly, we need, and praise, that kind of argumentation on the general level, both for political reasons and for group building. One might ask how this wow-factor is to be understood. However, this article will stress what I term the how-factor, which involves how creativity is to be understood. How is research conducted in the arts? What is the link between process work, judgment, evaluation, cultivation, collection, innovation and creativity? While I do not fully answer these questions, I provide a site where such questions could be discussed further. It is my intent to pulverize the schemata that set up the following dichotomies: creativity as opposed to systematic work, creativity and play as opposed to hard work and fantasy as opposed to rationality. How do we recognize and plan for quality in arts education? Is it possible that focusing on the series will have consequences to our ability to "read" art as such? I am certainly not the first to address the question of quality. However, instead of stressing that creativity is important, and that creativity is about invoking the whole of the body, I examine a focused, specific sector of art work, namely series work, as a site for the quality discussion.

Finally, this focus on the art series will contribute to some closing reflections on how the series, as a phenomenon, might build theory into artistic research. 
The article builds on the following hypotheses: First, the series is a site of reflection located within the art field itself, a reflection that is of significant interest to artists, art historians and teachers of the arts. Second, evaluation is not merely stated through serial works of art, it is shown. Third, the series is a topos of theory building in artistic research. For this discussion, we need examples of the series in arts production.

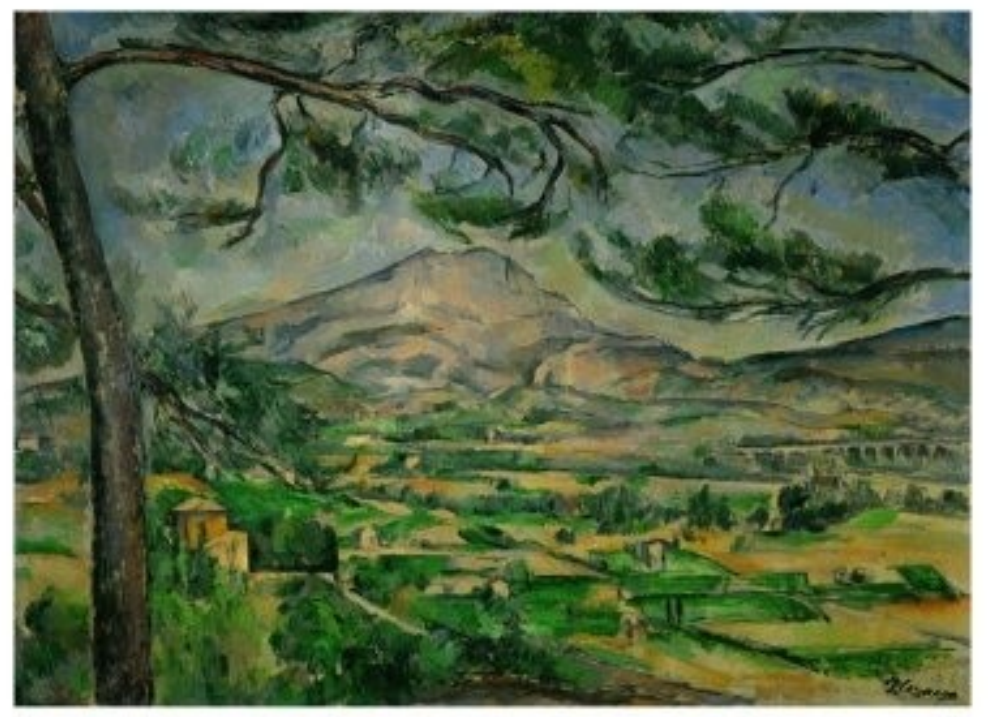

Figure 2. Paul Cézanne: Mont Sainte-Victoire

\section{Examples of serial works of art}

Working in his studio, near Aix-en-Provence, the French artist and painter Paul Cézanne (1839-1906) painted portraits, still-life paintings of fruit, and last, but not least, Mont Sainte-Victoire. In fact, he painted the Sainte-Victoire motif repeatedly, over and over again. None of the paintings give any precise indication of what time of the day it is, or even what season it is. There are no people wandering on the footpaths and no animals to be seen. As the art theorist Kjersti Bale stresses, in that the landscapes do not resemble actual nature; they are more like Cézanne's still-life paintings (Bale, 2009 , p. 120f). This means that the focus is on the composition, the forms, the colours and the brush strokes. Art does not resemble, instead it catches and creates the materials of the art forms themselves. To me, the Mont Sainte-Victoire series of paintings looks like a research project, an artistic research project. It appears that Cézanne is researching form through the use of colour, composition and brush stroke.

We might ask whether a theory exists for this kind of research. Indeed, art historians analysed this series of paintings from the outside, and in doing so developed the theory of impressionism. Many of the works in this series are also reflected in verbal texts about the work processes, thus providing links to traditional art theory. However, my question here is whether theory is also embedded in the series itself, in the principles that the artist might discover in his or her exploration of the complexity of human visual perception, or in the brushstrokes, composition and colour. Such a perspective turns painting into theoretical work as well as art practice. If that is the case, we can talk about theory both in a verbal form and in an artistic form; and we can discuss the interface between the two. We find serial work in all kinds of art; pottery is just one example. 


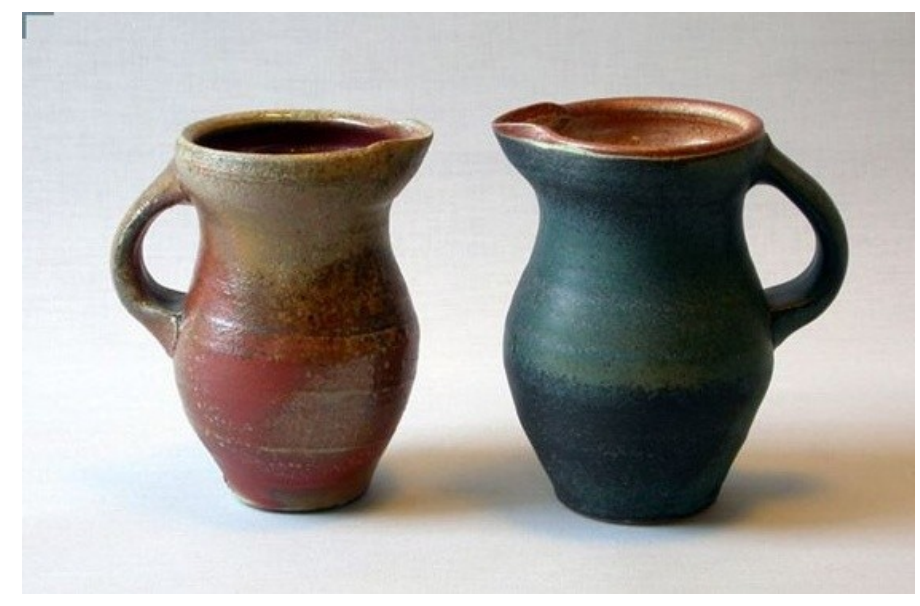

Figure 3. Elisa Helland-Hansen: Pitchers

(C) Elisa Helland-Hansen / BONO

Over the years, the ceramic artist Elisa Helland-Hansen (www.elisa-hh.no) has made tremendous collections of pitchers. The pitchers resemble each other. The shape is the ultimate shape, like a signature, developed through pottery traditions, use and years of experimentation. The shape suggests a combination of aesthetics and functionality. However, we might ask, what is it that differentiates between this and mass production? It is as if the potter is experimenting with slight variations in the stoneware, the heat (fired for 8 hours at 1300 degrees $\mathrm{C}$ ) and the stove (a wood-fired kiln), as well as exploring how colouring and glazing as chemical processes meet the clay as a natural material to produce a harmonious form and function. We might say that the series is a site where one can grasp differences among otherwise similar objects. In that they are also the result of experiments in the materials themselves, it appears as if some differences are not fully controlled by the artist. It is as if there is a dialogue between the artist and the material; in this dialogue, the material is frequently the dominant influence.

A third example of serial work is found in some of the work by the Norwegian sculptor Bård Breivik. He produced a series of objects in a wide variety of materials, including black car varnish and polished steel. All of the pieces are shaped like a boat, $60 \mathrm{~cm}$ long; they are equal in length, but different in material, colour, shape and surface. According to Breivik, "The format is just perfect - too big to be an object and too small to be a sculpture" (Kaminka, 2005, p. 27). Breivik calls this series Score for a longer conversation. It is like a series of polished arguments; like arguments, it is part of a longer and continuing conversation.

One might ask what makes us experience the row of objects as a series. I presume that we look for resemblances in the objects. All of them have the same basic shape. Breivik explains that the length is $60 \mathrm{~cm}$, a functional size if they are to be carried on a plane. In a classical sense, that type of argument in artistic work implies a practical techne, a production aesthetic linked to craftsmanship. Nonetheless, the differences between the objects are also obvious when they are put together, as shown in figure 4 . They are made of different materials (thread, steel, hard wood or ivory), treated differently (polished, painted, varnished, coloured or rubbed), and have slight differences in shape within the basic shape (curved, convex, inverted or straight and narrow or wide, all of which are symmetric). All of these variations trigger a visual image and a tactile experience. One viewer remarked that this series reminded him of catching trout and salmon, and that it stimulated the desire to intervene and hold. Taken together, this is a disciplined experiment, a kind of "quantitative artistic research". Breivik works with some variables, which he manipulates, while others remain fixed. By calling it a 
conversation, he highlights the relationship between the objects. Breivik also experiments with the combination of objects, for example, by reducing the number of variables by keeping only the objects in a black and white scale, thereby developing what might be called a score of a longer sad conversation.

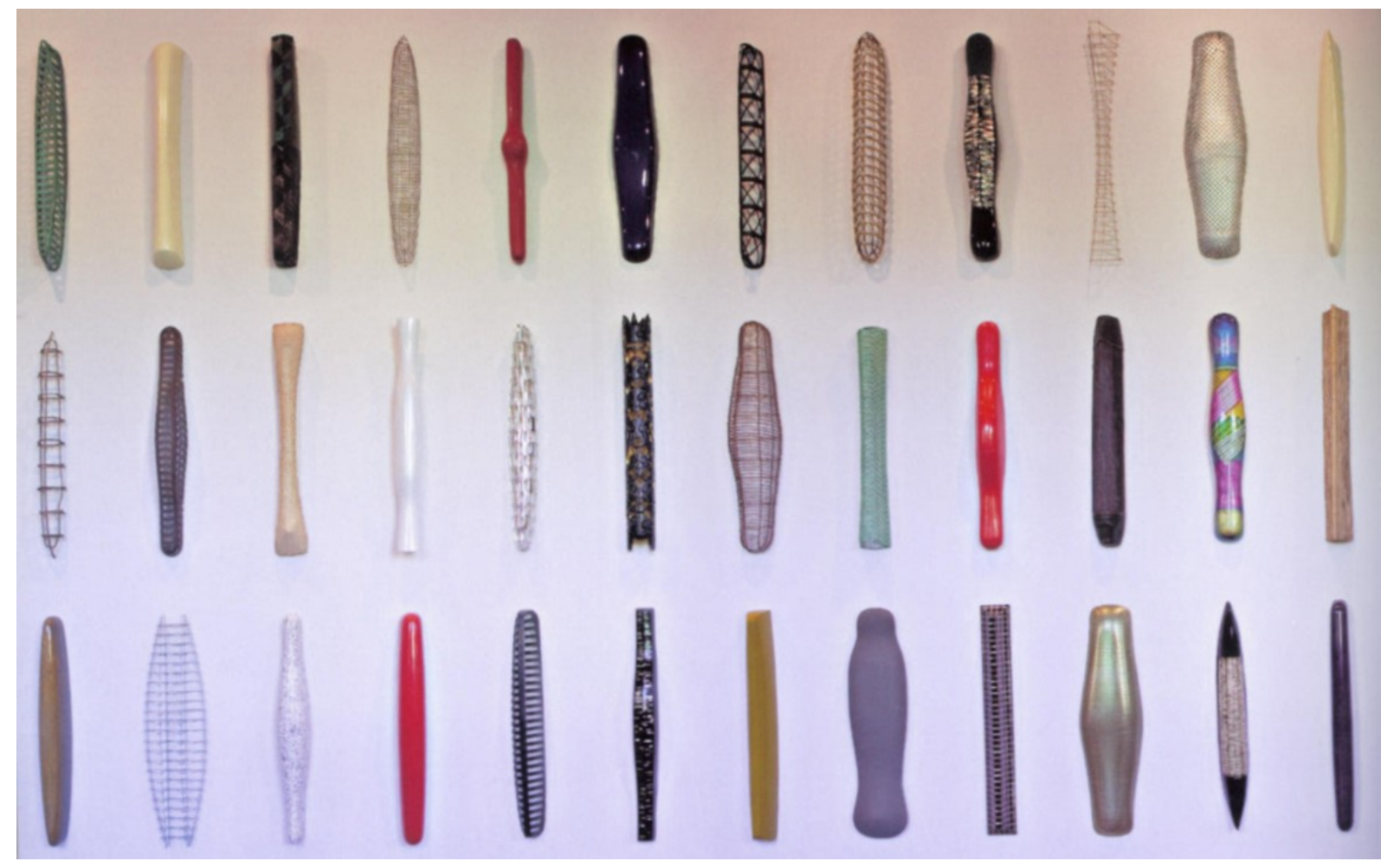

Figure 4. Bård Breivik: Score for a longer conversation (C) Bård Breivik / BONO

Although serial work is found in all types of art, it is important to stress that in our reflections we should not jump too quickly from one art form to another. The visual, the tactile and the audible may all present different challenges. Moreover, the examples presented here might look similar in that the series is the work of a single artist creating a series of at least 20 of a kind. One might also discuss what the differences are between presenting a working process and presenting a series of work (Stiles \& Selz, 1996). In this article, I focus on specific examples that have an autonomous status within the artist's productions. One might ask whether two of a kind is a series. Does the concept of a duo, as developed by the artist Felix Gonzalez-Torres, alter the way we think about the similar and the different (Bourriaud, 2007, pp. 69-75)? Although many of Gonzalez-Torres' works consist of two of a kind, the duo is not a binary opposition; instead, the artist stresses the couple as a quiet and calm unity, such as an ellipse. Finally, is the series a positive figure; is it actually something positive, such as in Deleuze's figure ritournelle - a repetitive refrain (Bourriaud, 2007, p. 141f)? We keep these questions about the possible limits of a series in mind in the following theoretical discussions.

\section{The series - some theoretical reflections}

The concept of a series, as examined through examples from Pinturicchio to Breivik, raises questions that are central in the discourse of the history of art. In examining the series, we might ask what can be 
learned from them about artistic work and artistic research. It is evident that the perspectives are different, depending on the epistemological and philosophical position from which we reflect. Interpreting the series as a figure is linked in complex ways to the notion of originality in art, the changing of values, the development of mechanical reproduction and the notion of art as consumption. In the following discussion, I provide a glimpse of how serial work, copying and sampling are understood - based on the ideas of Walter Benjamin, Michel Foucault and Gilles Deleuze, as well as the classical rhetorical tradition.

Walter Benjamin's essay "The work of art in the age of the mechanical reproduction" (1936) is a pivotal text in this discussion. In principle, a work of art has always been reproducible. Nevertheless, Benjamin states, "mechanical reproduction of a work of art, however, represents something new" (Benjamin, 2007, p. 30). The foundation of Benjamin's argument is that art suffers from what he calls a decay of the aura and a loss of authenticity when reproduced by the new methods available in the age of modernity, "That which withers in the age of mechanical reproduction is the aura of the work of art" (op. cit. p. 31). Benjamin maintains that the nature of the repercussions that these two different manifestations - the reproduction of works of art and the art of film - have had on art in its traditional form is revealing. The change from manual reproduction to technical reproduction and the change from a focus on the cult value to a focus on the exhibition value have both had a tremendous impact on mass production. The first is linked to art as part of a ritual, as with our example from Pinturicchio, while the second is linked to the development of the market.

Nonetheless, these perspectives on the decay of the aura do not clarify the role of reproduction and copying in preromantic times. For instance, in the rhetorical tradition, copying had to do with copia a rhetorical term meaning stock, store, supply, inventories and archives; specifically, something truly positive and not secondary or inferior as we typically regard copying today. In the rhetorical tradition, it was important to reproduce the best patterns and formats, and to choose the best ones in every new situation at hand. Consequently, the rhetorical perspective encouraged serial thinking and serial work.

The concept of the series, as we understand it today, has evolved with the different historical settings. One might argue that the phenomenon ends up being a paradox in the age of the avant-garde. Ina Blom states in her study of early avant-garde movements (Dadaism, Constructivism, Futurism) that repetition is the historical condition under which the irruptive event-character of these works is produced (Blom, 1999). Blom's study puts forward and discusses the concepts of repetition, the event, the logic of seriality, singularity and the unique in ways that put the series as a figure in the didactics of arts at the very centre of the avant-garde discourse.

According to Foucault and the way he is interpreted by Deleuze, there are two kinds of serial thinking, or two concepts of series. ${ }^{2}$ Specifically, there are two kinds of series because there are two kinds of repetition.

The traditional series is built on resemblance. ${ }^{3}$ According to Foucault,

The resemblance has a "chef": An original element that gives orders and makes hierarchies according to itself and all the weaker and weaker copies you could imagine of the first one. To resemble presupposes a first referent that prescribes and classifies... Resemblance finds its orders in a model it has to return to and make recognizable.... Resemblance means a unique confirmation, always the same (Foucault, 2001, p. 50f)

\footnotetext{
${ }^{2}$ This presentation is strongly indebted to Eliassen's (2001) readings of Deleuze and Foucault (2001).

${ }^{3}$ In Norwegian, it is "likskap".
} 
Therefore, we could say that to resemble means repeating by comparing to an original version, a prototype, an ideal, a model or a mother pattern in a classical mimetic way.

Among the examples above, we might read Pinturicchio's Madonna with the child as this kind of series. There is an ideal, a religious ideal of a mother and a child, and the series consists of different copies of that ideal. This method of reading the series corresponds to interpreting art from the classical point of view. The series has a sameness with the ideal, and new copies fall into the same order. The consequence is that it is not the series that is interesting, but the identification of the copy that can be rated as the best one. The classification is based on one original version, in this case, by an ideal inscribed in the tradition itself.

In contrast, what happens if we read the series from the point of view of the artist? There is no doubt that Pinturicchio is devoted to a religious theme. From a literary perspective, the mother model is Maria. However, the experimentation, the slightly different compositions and variations in the clothing and the background make the differences between the paintings the interesting feature.

Through the artist's performative aesthetics, experimentation through form, we can grasp another kind of serial thinking, that which, according to Foucault and Deleuze, is built on similitude, or the uniform. ${ }^{4}$ Foucault states:

The uniform unfolds in series that has neither start nor end, series that one can cross in one direction or the other, that does not obey any hierarchy, rather spreads from small differences to small differences.... [T]he uniform serves the repetition that runs through it... The uniform manifolds different confirmations that dance together as they both support and fall from each other (Foucault, 2001, p. 50f).

We understand that the uniform (or the similitude) is not identical, not mimetic. Every new variation juxtaposes sameness against a background of difference. What is interesting is the difference. Every new variation changes our perception of the series. It changes the principle of the series. The new category does not exist before the series; instead, it is generated out of it. This secondary similitude, the other type of resemblance, is aesthetic in the accepted meaning of the word. It is developed in the sensuous surface of the material and pragmatic in the way that it is a consequence of practice, always dynamic and open for corrections. Deleuze writes about the stammering in culture, while Eliassen uses the word rhythm to describe this kind of relationship between the elements (Eliassen, 2001, p. 120).

Breivik's series, Score for a longer conversation, illustrates the latter type of serial thinking. In it, the uniform is not identical; it does not have a prototype. Instead, it sets sameness up against a background of difference. All of the objects are to be understood on the same level. In Foucault's words, the series is constituted of elements playing - or dancing - together. It could be characterized as a form of rhythm. Is that not the core of a conversation - the rhythm of what is happening between the words, a poetic rest?

Foucault states, "The resemblance serves the representation that rules through it; the similitude serves the repetition that runs through it" (Foucault, 2001, p. 51). Here we notice the expressions "rules through" and "runs through". "Rules through" is hierarchical, based on a mimetic principle, linked to the idea that first, there is the idea, and then we create the form. In contrast, "runs through" is not identical, not abstract, but down to earth and practical. In that it stresses the sensuous surface, it is

\footnotetext{
${ }^{4}$ According to Eliassen (2001, p. 126), the word for "resemblance" is "likskap", while the word for "similitude" is "det einsarta". The reason for this is that the latter expression connotes an outer, more physical and exact kind of accordance (samsvar). In contrast, "likskap" allows for greater kinds of difference, and is connected more frequently to signs of the significant. According to Eliassen, this implies some kind of thinking or some kind of synthesis (Eliassen 2001, p. 126).
} 
aesthetic in the basic understanding of the word; and it is pragmatic in the sense that it is a consequence of practice. The former is platonic and metaphysical, while the latter is physical - not platonic, and not mimetic.

Based on these reflections on the series, the way in which the practice of comparison and judgment (instead of total freedom) is at the core of artistic work may seem surprising. According to Foucault, in the series, you either compare the works to an ideal outside the series, or you develop comparisons within the series - or you may do both.

The operation of comparison is directly related to the concept of "doxa", which we find in the expressions "common sense", "good sense" and "good taste". In rhetoric, however, doxa is a complex term. It has to do with the archive of the culture, and the canonization of patterns and forms. It also has a temporal aspect: doxa constitutes the sense of common time, our time, thereby making something part of the contemporary. Finally, yet quite importantly, we have the doxa of representation. As Poxton and Stivale (2005) stress in their presentation of Deleuze, "common sense" expressed in the formulation "everybody knows", assuming the existence of a universal cogito: a knowing subject whose rational thought displays a natural affinity for truth. "Within the domain of common sense, then, knowledge is reduced to recognition.... Recognition and common sense function to domesticate differences" (Poxton \& Stivale, 2005, p. 65f). Doxa is present in conversations, as well as in short expressions (locus communis or common places), for example, "as you know", "it's obvious" and "at present time". Philosophers, however, think differently about the concept of doxa. In the rhetorical tradition, knowing the archive and the register of forms is the first step in developing that same archive. Some of the leading philosophers' views of doxa can be summed up as follows: According to Pierre Bourdieu, cultural distinctions are socially constructed. Roland Barthes states that doxa is systematized stupidity (la Betise), a stupidity that adheres to everything: knowledge, culture, science and even your own thinking. The only way to escape is through motion. Foucault is interested in what the episteme does not allow us to see. Karl Marx writes about false superstructure. Walter Benjamin explores the waste of culture, searching the fragments for items of value; and building archives of the curious, of things that are odd. Thus, the concept of doxa is the clue to understanding the order of knowledge - and the practice of evaluation.

The series is seen as a site for this practice of evaluation. To Deleuze, the series is important because it instantiates a mode of organization of difference that avoids the pitfalls of representation, within which differences are tamed by the mechanisms of resemblance, identity, analogy and opposition (Poxton \& Stivale, 2008, p. 68).

\section{The series - a site of evaluation in arts education}

During the 2010 Easter season, the British Museum in London exhibited some figures from the Chinese terracotta army. In the lobby, there was a display of representations of that army made by children visiting the exhibition. The children's copies were both a production and an interpretative response, or to be more precise, the productions were reading responses. In the didactics of art, this points at an important and well-known way of working - to combine the viewing and production of art. 


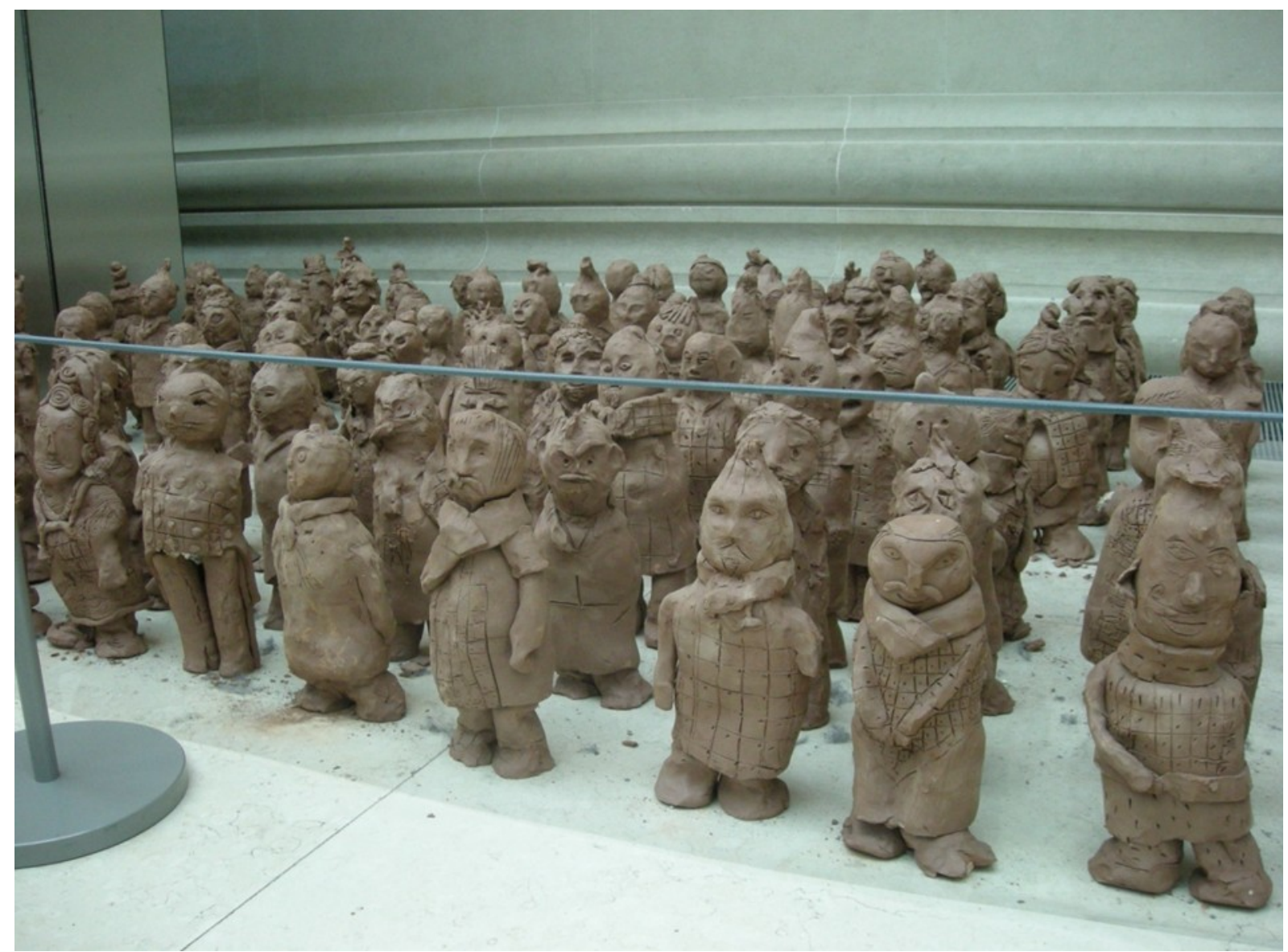

Figure 5. Children's copies of the Chinese terracotta army. Photo: Aslaug Nyrnes.

The serial terracotta figures point to a well-established contrast in the history of the didactic of arts and crafts in Norway. To copy canonized patterns was the basis of arts and crafts in the Norwegian schools from the late 1800s. Pupils copied something that was going to be useful (Nielsen, 2009, p. 109-110). This was seen in all aspects of the field - in woodcraft, knitting and drawing, as for instance in sketchbooks for children (Økland, 2012). In the 1960s, the focus shifted from this copying culture to one of stressing the importance of the individual pupil's freedom and creativity. Copying patterns as a technique and a way of thinking was now discredited.

Nonetheless, the children's terracotta figures may remind us that pattern, copying and serial work are part of an old, classical tradition. To work with a series is not only to produce something that looks alike, but it also involves getting to know the patterns and the archives of a culture. From the perspective of the rhetorical tradition, this store is not opposed to creativity; instead, creating is dependent on just such a knowledge of tradition. Hence, working in series might give us access to cultural evaluations in an extremely fundamental as opposed to a superficial and trivial manner. So how is this to be understood?

I do not know whether each child made only one or many of the terracotta figures. However, if we allow one child to make many in a row, we promote his or her quality judgment. The individual child alone does not govern the situation or the production; nor does the teacher. The clay, the heat (fired for 8 hours to 1300 degrees C) and the kiln also govern the child's work. S/he is exploring the relationship between colour and surface, form and function. We are at the core of the aesthetics of production. Working in series develops forms of internal evaluation. Given that a series is a site for the practice of evaluation, we may ask how it may also be a site for promoting quality in arts education. 
For the most part, we think of the core of art as being a unique and singular expression. However, if art is unique, the series should not be understood as being in opposition to one of a kind; rather it represents a new way of considering plurality. The series highlights the change and plurality inscribed in objects that simultaneously resemble one another and yet are different. In the series, evaluation is linked to the form of the art object itself. Evaluation is inscribed in both the production and the reception of art. A series will reveal the evaluation implicit in the art form itself. One might think that working in series narrows creativity. However, creativity is not freedom as such; creativity is about developing possibilities within a framework, while also challenging aspects of the framework.

The child's evaluation is additionally linked to - or it might even be governed by - their imagination and reflection outside the art object. In this context, the key questions concern whether the child is encouraged to make a fixed copy, or encouraged to experiment within the form. Reflections will evoke whatever form is available in the tradition that the teacher and the child are able to activate.

These reflections are not to be understood as an indication that the series represents quality per se. Instead, we might look upon the series as a site for developing, promoting and discussing quality. This promotion is twofold.

First, the series may develop artistic value as creative difference - through the material, the production and the object. A series is a row of examples. Depending on our theoretical frame, we may read the examples variously as illustrations of the original terracotta army, as revelations of the quality discussion, or of the resemblances and differences. In the series, pupils experience the differences. Artistic work implies specificity and singularity. However, in order to develop distinctions, one has to concentrate on the small differences. This means that one makes "similar" objects; and that the interesting aspects are the differences between the objects - not the features that make the objects resemble each other. One might also say that the series serves the difference, and highlights its own empty space, the space between the objects. Art didactics is in this row of concrete examples, incorporated into their very forms. As Aristotle wrote in Rhetoric, good examples are greater than themselves; this is because what has happened tends to repeat itself. Rimbereid expands on this perspective by pointing out, "at the same time, no examples can become greater all by themselves" (Rimbereid, 2006, p. 31). Thus, the examples in the series do not carry a "natural" truth: such is a terracotta army. However, by continually producing new examples, we can think through new forms, thereby developing and adding nuances to the idea.

Second, the series is a site for the verbalization of this quality discussion, a verbalization that should be encouraged. After all, the ability to read and verbalize what you see is the first prerequisite for all student work. Through the series, we can develop the students' competence in reading art. This competence is about precision, about details mattering, and about forms serving as methods of categorizing and organizing things. Precision in detail is at the core of the arts disciplines. Reading details is not just an end in itself; it is a means of developing the ability to read art thoroughly and precisely. Learning how to read details is to learn how to read variety. It is to develop a respect for differences. It is to train oneself to see how cultural weight and variations are incorporated into linguistic order, thereby shaping what we see.

\section{The series as a site of theory building in artistic research}

Serial work is artistic research. My final hypothesis is that the series is especially interesting as a site for building theory in artistic research. This type of statement triggers concepts associated with both artistic research and theory. 
Artistic research is an internationally established term. ${ }^{5}$ Even in this type of research, it is not uncommon to think of theory as central ideas from art history or aesthetical philosophy that informs the artist in his or her work. However, the question is whether artistic research involves any special kind of theory building developed through artistic practice.

Theory concerns some kinds of ideas and principles. We typically regard theory as a verbal form an analytical principle outside the research object, in short, the theory found in theory books. It may be regarded as a special world-view, a set of notions combined to form a reasonable cluster. This means that theory is ideology, a common means of viewing the world, a problem, an object or an action.

Since artistic work is a matter of singularities, one may ask how it can be systematic at the same time. Artistic researchers stress reflection as the core of the research process. I would maintain that one can discuss theory in art's own language, and that it is legitimate to talk about the principles revealed in the study of a series of artistic works as a form of systematic language. Theory is revealed within the principles that can be pinpointed in the collective of examples at hand. Moreover, when an artist works in series, he or she is both aware of/and experimenting with certain principles. This means that this kind of theory leads to a comparative view, rather than induction or deduction. Thus, theory in an artistic production also concerns the series of other productions to which the one at hand is referring.

Therefore, my last claim is that the series is a topos for developing theory in artistic research. Through the series, we are building what we might call a minor theory - to use an analogous expression introduced by Deleuze. The development of these types of systematic similarities in art research is a matter of developing poetic similarities and differences. This way of understanding artistic research may help us develop and strengthen our understanding of how comparisons and evaluations come about or are established. Therefore, studying artistic serial work may highlight art as a site for doing philosophy of research - art as a site for profound reflection in the humanities.

\section{Closing remarks}

The goal of this article was to focus on the series as a site through which discussions of artistic work, artistic research, didactics of art and the promotion of quality meet in a concrete way. First, the series is a paradoxical figure in art and in the didactics of art. It is, on the one hand, a phenomenon from popular culture, stating second order value; but on the other hand, in the classical tradition, copying is also positively valued, in the sense of copia - rich archive, variety and fulfillment. Second, the series is a site where small differences between objects that are either the same or of a kind call the core of variety into question. This means that we can come to grips with our own evaluations. Finally, the principles that run through a series challenge the artist working through it, thus opening up the potential for the development of theoretical perspectives.

\section{Presentation of contributor}

Aslaug Nyrnes studied literature and rhetoric at the University of Bergen, and is professor, dr.art in the didactics of literature and fine arts at Centre of arts, culture and communication, Bergen University College. Her research interests are literature, rhetoric and the epistemology of artistic research. At the

\footnotetext{
${ }^{5}$ The research field is growing rapidly through examples of artistic research (Journal of Artistic Research, JAR) and through the debate on the status and ontology of the field. A late overview can be found in Borgdorff, 2012. As for the Norwegian field and the use of the term "kunstnerisk utviklingsarbeid", see Malterud, 2012. Regarding artistic research in a rhetorical perspective, see Nyrnes, 2006.
} 
college Nyrnes is the leader of the research program "Kunstfagdidaktikk" (2009-2015), a program that includes researchers in drama, music, dance, arts and crafts, media and literature. From 2010-2014 Nyrnes is the leader of the steering committee of the national Program for Artistic Research (www.artistic-research.no).

\section{References}

Bale, K. (2009). Estetisk teori. Oslo: Universitetsforlaget.

Bamford, A. (2006). The wow factor: Global research compendium on the impact of the arts in education. Münster-Waxmann.

Benjamin, W. (2007 [1936]). The work of art in the age of the mechanical reproduction. I Mathijs, E. \& Mendik, X. (Ed.). The Cult Film Reader (pp. 29-40). Berkshire: Open University Press.

Blom, I. (1999). The Cut Through Time. A Version of the Dada/Neodada Repetition. Dissertation for the Degree of Dr. Art. UiO: Faculty of Arts. Acta Humaniora nr. 55.

Borgdorff, H. (2012). The conflicts of the faculties. Perspectives on artistic research and academia. Amsterdam: Leiden University Press.

Bourriaud, N. (2007). Relasjonell estetikk. Originalens tittel: Esthétique relationelle. 1998. Omsett av Boel Christensen-Scheel. Oslo: Pax forlag.

Eliassen, K. O. (2001). Etterord, I. \& Foucault, M. Dette er ikke en pipe. Med illustrasjoner og brev av René Magritte (pp. 77-127). Oslo: Pax forlag.

Foucault, M. (2001). Dette er ikke en pipe. Med illustrasjoner og brev av René Magritte. Oslo: Pax forlag.

Kaminka, I. (2005). Hvordan begynte det? Samtale med Bård Breivik. I Vortex. Works in progress. Bård Breivik. Nye skulpturer og installasjoner. Oslo: Nasjonalmuseet for kunst, arkitektur og design. (pp. 18-29).

Malterud, N. (2012). Kunstnerisk utviklingsarbeid - nødvendig og utfordrende. InFormation. 1/2012.

Nielsen, L. M. (2009). Fagdidaktikk for kunst og håndverk. I går - i dag - i morgon. Oslo: Universitetsforlaget.

Nyrnes, A. (2006). Lighting from the side. Rhetoric and Artistic Research. Sensuous Knowledge Series. No 03/2006. Bergen: Bergen National Academy of the Arts.

Pintoricchio. (2008). Perugia: Galleria Nationale dell’Umbria. 2. Febraio - 29 giugno. Danae FLM Production. http://www.danae.it.

Poxton, J. L. \& Stivale, C. J. (2005). Sense, series. I Stivale, C. J. (Red.). Gilles Deleuze. Key Concepts (pp. 65-76). Chesham: Acumen.

Rimbereid, Ø. (2006). Hvorfor ensomt leve. Essays. Oslo: Gyldendal.

http://www.elisa-hh.no.

Stiles, K. \& Selz, P. (Ed.). (1996). Process. I Theories and documents of contemporary art. A Sourcebook of Artists' Writings (pp. 577-678). Berkeley: University of California Press.

Økland, E. (2012). Norske malebøker. Laremiddel, kunstformidling, tidtrøyte og lokkemiddel. Oslo: Samlaget. 